\title{
Ozyegin University Example: Responsible Consumption \& Responsible Stakeholders
}

\author{
Tugba Cubukcu ${ }^{1,}$, , Ceren Demircir ${ }^{2}$ \\ ${ }^{1,2}$ Ozyegin University, Turkey \\ * corresponding author: tugba.cubukcu@ozyegin.edu.tr
}

\section{Article Info}

\author{
Received: \\ 15 March 2021 \\ Accepted: \\ 25 May 2021 \\ Published: \\ 1 August 2021 \\ DOI:
}

Presented in The $6^{\text {th }}$ International (Virtual) Workshop on UI GreenMetric World University Rankings (IWGM 2020)

\begin{abstract}
Sustainability has been one of the core principles at Ozyegin University (OzU) since its establishment in 2008 and is deeply embedded in its education, research and governance strategy. For $\mathrm{OzU}$, being a green university means building an organic community constantly improving itself on every aspect of sustainability in collaboration with all its stakeholders. $\mathrm{OzU}$ accomplished these by establishing the first Health \& Safety and Environment (HSE) Department within a university in Turkey. Besides, OzU is also the first university in Turkey to have been concurrently awarded both ISO 14001 Environmental Management System and OHSAS 45001 Occupational Health and Safety Management System Certifications. With these accomplishments $\mathrm{OzU}$ has pioneered the path for sustainable universities in Turkey resulting in various rewards and highest places in multitude rankings including GreenMetric. This paper discusses OzU's strategy and the subsequent steps taken to attain these achievements including the roles of HSE Department and HSE Board.
\end{abstract}

\section{Keyword:}

sustainability, higher education institutions, green university, Turkish universities

\section{Introduction}

Devoting to address the challenges of the SDGs demands new insights, new ways of doing things, hard choices between competing options and fundamental changes in some cases. Universities demonstrate how to support, adopt and implement SDGs by not only their basic responsibilities -education and research- but also with the roles they adopt in governance, operations and culture in delivering their basic services. Sustainability has been one of the core principles at Ozyegin University $(\mathrm{OzU})$ since its establishment in 2008 and is deeply embedded in its education, research, and governance strategy. For $\mathrm{OzU}$, being a green university means building an organic community constantly improving itself on every aspect of sustainability in collaboration with all its stakeholders. OzU accomplished these by establishing the first Health \& Safety and Environment (HSE) Department within a university in Turkey. Besides, OzU is also the first university in Turkey to have been concurrently 
awarded both ISO 14001 Environmental Management System and OHSAS 45001 Occupational Health and Safety Management System Certifications. With these accomplishments $\mathrm{OzU}$ has pioneered the path for sustainable universities in Turkey resulting in various rewards and highest places in multitude rankings including GreenMetric. This paper discusses OzU's strategy and the subsequent steps taken to attain these achievements including the roles of HSE Department and HSE Board.

\section{Sustainabilty and Higher Education Institutions}

The key role of higher education institutions in the transition to a more sustainable society has been recognized and highlighted for almost four decades [1]. In respect to the planetary sustainability challenges [2], universities are identified as key actors for innovation and environmental education, and they present an opportunity for enabling the generational behavioural change toward taking on more sustainable attitudes in daily lives $[3,4]$. To be credible in this role, the university has to behave responsibly in the management of the energy and human resources of the campuses. A sustainable university has been defined as a higher educational institution that addresses, involves and promotes, on a regional or a global level, the minimisation of negative environmental, economic, societal, and health effects generated in the use of their resources in order to fulfil its functions of teaching, research, outreach and partnership, and stewardship in ways to help society make the transition to sustainable lifestyles [5]. Cole highlighted the key role of sustainable campus communities, since "they actively engage the knowledge of the university community to address the ecological and social challenges that we face now and in the future" [6] (p. 30).

\subsection{Ozyegin University}

Ozyegin University (OzU) is founded in 2008. Since its initiation, sustainability has been one of the core values. Thanks to its unwavering commitment to protecting the environment, Ozyegin University has been playing a leading role among Turkish universities in 1) building an exemplary campus and designing a solid operational structure, 2) disseminating knowledge and creating awareness, 3) contributing to industry best practices. As a core principle of Ozyegin University $(\mathrm{OzU})$ since its establishment,sustainability is deeply embedded in its education and research strategy. Additionally, OzU believes that an university can have a direct influence with straightforward sustainable consumption and production strategies and practices aiming to ensure the efficient use of resources and therefore reducing the negative impact of economic activities on the environment. Thus, for $\mathrm{OzU}$, being a green university means decreasing our ecological footprint, prioritizing the environment and its future preservation in all our academic, scientific and operational pursuits and building an organic community constantly improving itself on every aspect of sustainability in collaboration with all its stakeholders.

As Turkey's very first university that is accredited with both ISO14001-Environmental Management System and OHSAS 18001, it has been the first university to have a Health, Safety and Environment unit in TurkeyThe university sees environmental awareness as a key element of its organizational culture. Hence, it is the primary responsibility of all academic and administrative directors to create and develop a mutual understanding, as well as shared beliefs, habits, and values among all stakeholders. It promotes and supports organizing training programs, seminars, events, and similar other activities to increase environmental awareness internally and externally. 
Since its initiation, all of the activities at Ozu, including research, education, civic engagement, and campus operations, reflect sustainability as core value. As a verification of its focus on sustainability, in $2017 \mathrm{OzU}$ collaborated with the Turkish Industry and Business Association to establish a Sustainable Development Forum and in 2018 signed the UN Global Compact concurrently with UN PRME. To address the lack of a centralized body leading to scattered efforts, in 2018, OzU Sustainability Platform is founded as a unit in order to coordinate, communicate and increase visibility of all activities related to sustainability as well as track and report all the academic and administrative arrangements related to these activities. This platform supervises sustainability research under 4 research clusters, provides support on educational content on sustainability for many courses, organizes several events to share knowledge with different stakeholders, to participate in and collect data of on camps and off campus social welfare and responsibility activities. The clusters are intended to propel OzU's capacity and experience in different fields of research on sustainability while creating an on-campus network for faculty with similar research interests, in particular to promote interdisciplinary cooperation and to understand the existing research needs on sustainability. To achieve this goal, Turkey's priorities for sustainability and OzU's strengths were combined together to form the following Clusters: i. Decent Work and Economic Growth, ii. Sustainable Cities and Communities, iii. Energy and Climate, iv. Social Equality.

At $\mathrm{OzU}$, all the members are expected to always act in the best interest of humanity by showing awareness about societal issues (environment, health, education, justice etc.). The same expectation extends to our students and they are expected to develop into successful leaders, innovators, as well as role models for integrity. Education at OzU reflects its commitment to creating awareness on sustainability. All the students entering Ozu are enrolled in ENG 101 and ENG 102 courses where the teaching material focuses on sustainability with an emphasis on UN's Sustainable Development Goals. Subsequently, there are courses offered on sustainability related with the programme the student is studying such as "Ecotourism" course in Hospitality Programme or "Sustainable Design and Environment through Biomimicry in Architecture Programme. In the Faculty of Business there are various courses to address sustainability. These courses include but not limited to "Sustainability in Business", "Diversity and Inclusion in Global Organizations", "Business Ethics", and "Business Ethics and Corporate Social Responsibility". As a matter of fact, $10 \%$ of all the curricula in $\mathrm{OzU}$ is dedicated to courses on sustainability. In addition, $\mathrm{OzU}$ collaborates with various parties in its sustainability efforts. The product of one of these most prominent ties is the OzU - TUSIAD Sustainable Development Forum (SDF) which is a joint initiative with TUSIAD (Turkish Industry and Business Association), the major business association in Turkey. The aim of the forum is to introduce new approaches and methods in order to propel sustainable economic development and smart industrialization while minimizing their adverse effects on society and environment. SDF carries out its activities with due consideration of the needs of the business world taking UN's Sustainable Development Goals as the basis.

Pointing out how sustainability was at the core of Ozyegin University since its foundation, Center for Energy, Environment and Economy (CEEE), in addition to research, teaching and service activities in sustainability, has been established in 2009 right after the foundation of the university in 2008. CEEE continuously develops innovative, practical, and open-source methodologies not only to cater to the existing needs and necessities, but also to identify and bring solutions to new needs stemming out from ever-changing dynamics. 
CEEE focuses on research and development projects which will have lasting impacts to sciences, engineering architecture, and to the society. All these research areas of CEEE are tied to 3 E's of the Center: Energy efficiency and harvesting, Environmental concerns and climate change, Economic impact and development. In line with the CEEE's focus on energy efficient buildings, $\mathrm{OzU}$ has developed green campus practices: three of OzU's campus buildings received the LEED Gold Certificate based on the measurements of the US Green Buildings Council. Moreover, the 3rd Academic Building or the School of Languages Building is renowned as one of Turkey's most energy efficient academic buildings. In addition to the LEED certificates, OzU is the first university in Turkey that has been concurrently awarded ISO 14001 Environmental Management System and OHSAS 18001 Occupational Health and Safety Management System Certifications. ISO 14001 provides organizations with an environmental management system to manage and enhance their environmental performance. OHSAS 18001 is an Occupational Health and Safety Management Certification which provides a framework to identify, control, and decrease the risks associated with health and safety within the workplace. Furthermore, OzU has $376 \mathrm{~kW}$-e solar panels installed in collaboration with Fina Energy as well as seven green roofs on its campus. Since its foundation, the University also houses an on-campus Energy Distribution Center, to manage all on-campus energy generation and consumption. The University also has comprehensive building automation applications along with well-organized water and waste management practices in place.

The emphasis of the university to be a green university is directly reflected in the architecture and construction of our campus. The three campus buildings out of four have been awarded highly acclaimed LEED GOLD certificates, showing the dedication of OzU to environmental sustainability. In addition, the fourth was constructed within the scope of the NEED4B "New Energy Efficiency Demonstration for Buildings", co-financed by the European Union. As a result, we lead the formation of standards for green buildings in Turkey by coordinating the Turkish Green Building Council. We try to restrict our carbon foot-print. We use wind power and solar panels on all the non-green roofs, as well as trigeneration system for heating and cooling.

Ozyegin University adheres the idea of a green university explicitly focusing on improving the impact that buildings and the campus have on the environment. In this direction, $\mathrm{OzU}$ cares about the integration of partnerships into education and research. The University has developed several initiatives with professionals and stakeholders. Among them, Sustainable Development Forum founded in 2015 with the collaboration of TUSIAD (Turkish Industry and Business Association) focuses mainly on sustainable development in the business world within the framework of SDGs. By being a part of this global agenda, OzU's objective is to build a strong dialogue, support the business world with its unique research competences while nourishing and directing its research areas through the developments and needs of the business world. OzU has a broader participation on societal problems related to Istanbul and Turkey. In 2010, OzU CEEE has organized the first Workshop on Istanbul'2050, which brought together people from all walks of society. At the end the Workshop highlighted the challenges Istanbul has been facing. Interestingly, 'the protection of the soul of Istanbul' was found to be the most pressing issue; in essence this was the prelude to 'sustainable cities' emphasis of the UN SDGs. In 2011 CEEE organized a Conference on Integrated Engineering and Architecture for Sustainable Buildings. It was cofunded by the US National Science Foundation (NSF) and the Turkish Science and Technology Council (TUBITAK). Since then CEEE is routinely organizing conferences and 
workshops on sustainable energy and human-building interactions for sustainable buildings. Since 2017, CEEE is also involved with the major effort called Sustainable Anatolia.

The University Administration and the Board of Trustees have agreed unanimously on making sustainability one of the pillars of University which is reflected on its new strategic plan 2018-2023. To this end, the University plans to develop more inter-, multi and transdisciplinary studies that combine the efforts of different academic and administrative units. These new initiatives will not only cover the academic curriculum but also include specific action plans to elevate the research output and impact to a higher level. Two OzU buildings are planned to have further contributions to the University sustainability efforts. OzU-X, a new open innovation coworking hub opened at the heart of the campus. A new Architecture Building is being constructed. This building is designed by combining all sustainable engineering-architecture principles with the sustainable energy emphasis. The University is continually reaching out to the world outside of the campus to transfer the new knowledge developed by its faculty and students to different sectors and businesses. Collaborations with TUSIAD, the plans of the new Center of Excellence for Industry 4.0 Competence and the research and the teaching efforts of the Center for Energy, Environment and Economy are all helping $\mathrm{OzU}$ to be one of the most impactful sustainable universities in Turkey and beyond $[7,8]$.

\subsection{Commitment}

As a fundamental indicator of commitment, Ozyegin University supports the implementation of the green university concept by having the principle "Environmental Awareness" as one of the core principles of the code of ethics. The university is financially committed to make sure that all its new buildings are environmentally friendly and fitting with the USGB standards. $376 \mathrm{~kW}$-e solar panels, seven green roofs, Energy Distribution Center, comprehensive building automation applications, and well-organized water and waste management practices are all fully covered.

Environmental protection, waste safety, and energy efficiency are firmly anchored in all practices at Ozyegin University as it sees environmental awareness as a key element of its organizational culture. Hence, it is the primary responsibility of all academic and administrative directors to create and develop a mutual understanding, as well as shared beliefs, habits, and values among all stakeholders. OzU also promotes and supports organizing training programs, seminars, events, and similar other activities to increase environmental awareness internally and externally [9]. Students conduct social responsibility and environmental protection projects with neighbouring communities, local governments and NGO's in mandatory SEC 101 courses. Furthermore, the university has recently founded Sustainability Platform as an integrated model to conduct and supervise sustainability related activities. This platform supervises sustainability research under 4 research clusters, provides support on educational content on sustainability for many courses, organizes several events to share knowledge with different stakeholders, to participate in and collect data of on camps and off campus social welfare and responsibility activities [10].

Ozu members also contribute to the implementation of green university concept through research efforts. OzU has created a series of research clusters to offer a multidisciplinary research environment and promote collaboration. Research clusters are intended to propel OzU's capacity and experience in different fields of research, to promote interdisciplinary cooperation and to understand the existing research needs. For instance, 
one of these clusters, "Energy and climate" cluster which is closely working with the CEEE specifically focuses on protection of the environment. CEEE has already funded by 5 EU, 1 USA, and several Turkish grants, totalling more than 2.5 million Euro funding.

\subsection{Impact}

As a result of its founding mission and strong commitment to becoming a green university, $\mathrm{OzU}$ has managed to generate an impressive record of environmental impact and outcomes. Last year, renewable energy produced at the university amounted to 402.175 $\mathrm{kWh}$ from solar system and $1.412 .652 \mathrm{kWh}$ from trigeneration system waste exhaust heat. The waste generated by Ozyegin university is fully recycled. In 2018, 138.5 tons of organic, 70 tons of packaging, 36.7 of compostable and 2.9 ton of electronic waste has been collected and sent for recycling. Packaging waste is collected separately and recycled by the university. All the organic waste including the plant matter are collected by the university and transferred by the municipality to the Sanitary Waste Storage where they are recycled. Compostable and electronic waste is sent to respective plants for recycling after collection.

$\mathrm{OzU}$ organizes various events to promote the environmental protection and disseminate knowledge in this field. In 2018, 875 OzU students received environmental training from HSE department. Furthermore, in "Sustainability Talks" seminar series, 8 talks about protecting the environment were organized by OzU Sustainability Platform. Furthermore, Ozyegin University is the first Turkish university that has ever participated in the ENO Tree Planting Day which takes place within the scope of ENO, the online global environment program launched in 2004 in the pursuit of planting trees and protecting the environment for sustainable development. More than 1800 trees were planted by $\mathrm{OzU}$ since the beginning of the program. In its efforts to promote environmental protection among multiple stakeholders, CEEE is currently working on several roadmaps including "The Methodology for Energy Efficiency in New Buildings" and the "Renovation Strategies for Energy Efficiency in Existing Buildings" with the help of two major European Union Projects, NEED4B and BRICKER.

In addition, CEEE has successfully completed several projects on energy efficiency literacy, infrastructure and impact funded by European Union, by Islamic Development Bank and other Turkish research authorities [11].

\section{Conclusion, Leadership role}

Thanks to its unwavering commitment to protecting the environment, Ozyegin University has been playing a leading role among Turkish universities in 1) building an exemplary campus and designing a solid operational structure, 2) disseminating knowledge and creating awareness, 3) contributing to industry best practices. As Turkey's very first university that is accredited with ISO14001 Environmental Management System it has been the first university to have a Health, Safety and Environment unit in Turkey. To create impact with research, $\mathrm{OzU}$ continuously develops innovative, practical, and open-source methodologies not only to cater to the existing needs and necessities, but also to identify and bring solutions to new needs stemming out from ever-changing dynamics. One of OzU's project done for local schools to create energy efficiency awareness has gone beyond current practice as by carrying the experience from Istanbul to Southeastern Turkey (10 more cities) in coordination with the Ministry of National Education and the Ministry of Energy. Morever, due to their success, OzU has already qualified seed funding from Islamic Development Bank in order to prepare energy efficiency road maps for countries in 
collaboration with decision makers from Tunisia, Mauritania, and Niger.

Under the roof of Sustainabilty Platform, the collaboration with the Turkish Industry and Business Association (TÜSIAD) in 2015 aims to introduce new approaches and methods in order to propel sustainable economic development and smart industrialization while minimizing their adverse effects on society and environment. All these units put the students at the center focusing on graduating $\mathrm{OzU}$ students as responsible citizens aware of and acting accordingly with the necessities of protecting the environment.

As a result of all these efforts, Ozyegin University was ranked the top Turkish university and $72^{\text {nd }}$ out of 450 universities in the overall category of the THE Impact rankings globally [12]. The University ranked 24th in the SDG 12 Responsible Consumption and Production category which focuses on the efficient use of resources and minimizing waste. THE Impact explores universities' food, waste, and recycling policies and practices towards this SDG. The University was also placed 48th in the SDG 11 Sustainable Cities and Communities scoring high for making significant contributions to urban planning through a series of research projects carried out by the Faculty of Architecture and Design, Faculty of Engineering, as well as CEEE. Over the years, Ozyegin University has shown its leadership and had valuable contributions to Turkey's environmental protection and sustainable development efforts believing that implementing the sustainable consumption and production patterns in its own governance, operations, and culture, the university directly contribute to promote resource and energy efficiency within its extensive spheres.

\section{References}

1. Maric, P.F., Meier, S.K., 1992. Theoretical Methods in Higher Education Institution. Education Journal, Volume 83-87, pp. 119-128

2. Seitzinger, S.P.; Svedin, U.; Crumley, C.L.; Steffen, W.; Abdullah, S.A.; Alfsen, C.; Broadgate, W.J.; Biermann, F.; Bondre, N.R.; Dearing, J.A. Planetary stewardship in an urbanizing world: Beyond city limits. Ambio 2012, 41, 787-794.

3. Tukker, A.; Emmert, S.; Charter, M.; Vezzoli, C.; Sto, E.; Andersen, M.M.; Geerken, T.; Tischner, U.; Lahlou, S. Fostering change to sustainable consumption and production: An evidence based view. J. Clean. Prod. 2008, 16, 1218-1225.

4. Jackson, T. Prosperity without Growth: Economics for a Finite Planet, 2nd ed.; Routledge: New York, NY, USA, 2011.

5. Hordijk, I. Position paper on sustainable universities. J. Clean. Prod. 2014, 14, 810-819.

6. Cole, L. Assessing Sustainability on Canadian University Campuses: Development of a Campus Sustainability Assessment Framework. Master's Thesis, Royal Roads University, Sooke, Victoria, BC, California, 2003.

7. Green, T.L. Teaching (un)sustainability? University sustainability commitments and student experiences of introductory economics. Ecol. Econ. 2013, 94, 135-142.

8. Zsóka, Á.; Szerényi, Z.M.; Széchy, A.; Kocsis, T. Greening due to environmental education? Environmental knowledge, attitudes, consumer behavior and everyday proenvironmental activities of Hungarian high school and university students. J. Clean. Prod. 2013, 48, 126-138.

9. http://surdurulebilirlik.ozyegin.edu.tr/en/project

10. http://surdurulebilirlik.ozyegin.edu.tr/en/sustainability-ozu/research

11. http://surdurulebilirlik.ozyegin.edu.tr/en/events

12. http://surdurulebilirlik.ozyegin.edu.tr/en/about-us

13. https://ecem.ozyegin.edu.tr/en 
14. https://www.timeshighereducation.com/rankings/impact/2019/overall\#!/page/0/lengt h/25/locations/TR/sort_by/rank/sort_order/asc/cols/undefined 